\title{
Nonsteroidal Anti-Inflammatory Drugs Promote Axon Regeneration via RhoA Inhibition
}

\author{
Qiao Fu, Jeongsim Hue, and Shuxin Li \\ Department of Neurology, University of Texas Southwestern Medical Center, Dallas, Texas 75390
}

\begin{abstract}
After a CNS injury in the adult mammals, axonal regeneration is very limited because of the reduced intrinsic growth capacity and nonpermissive environment for axonal elongation. The growth inhibitions from CNS myelin and astroglial chondroitin sulfate proteoglycans partially account for the lack of CNS repair. Here, we show that the nonsteroidal antiinflammatory drugs (NSAIDs) ibuprofen and indomethacin, the drugs widely used as pain relievers in the clinic, can surmount axon growth restrictions from myelin and proteoglycans by potently inhibiting their downstream pathway RhoA signal. Similar to Rho and Rock inhibitors C3 transferase or Y27632 $[(R)-(+)-$ trans- $N$-(4-pyridyl)-4-(1-aminoethyl)-cyclohexanecarboxamide], both NSAID drugs stimulate a significant neurite growth in the cultured dorsal root ganglion neurons exposed to the inhibitory substrates. Systemic administration of ibuprofen to spinal cord-lesioned rodents reverses the active RhoA signal around injury area measured via Rho-GTP binding assay. Subcutaneous injections of ibuprofen via minipumps to rats with a thoracic spinal cord transection or contusion injury result in substantial corticospinal and serotonergic axon sprouting in the caudal spinal cord and promote locomotor functional recovery, even delaying the treatment 1 week after trauma. In contrast, the non-RhoA-inhibiting NSAID naproxen does not have the axon growth-promoting effects on cultured or lesioned neurons. These studies demonstrate the therapeutic potential of RhoA-inhibiting NSAIDs in treating CNS injuries characterized by axonal disconnection including spinal cord injury.
\end{abstract}

Key words: axonal growth; spinal cord injury; myelin; chondroitin sulfate proteoglycans; ibuprofen; indomethacin

\section{Introduction}

Axonal connections between neurons and their synaptic targets are essential for maintaining nervous system function. Disconnection of axons usually leads to signal conduction failure and persistent severe functional deficits in such patients as white matter stroke, progressive multiple sclerosis, traumatic brain injury, as well as spinal cord injury (SCI). In the adult mammalian CNS, the severed axons do not regenerate to any appreciable degree after injury primarily because of the reduced intrinsic growth capacity of adult CNS neurons as well as a poor environment for axonal regeneration (David and Aguayo, 1981; McGee and Strittmatter, 2003). Several factors contribute to the nonpermissive nature of the injured adult CNS for axonal growth. Chondroitin sulfate proteoglycans (CSPGs) generated by astroglial scar tissue around lesion suppress axonal extension (Bradbury et al., 2002; Silver and Miller, 2004). CNS-myelin-forming oligodendrocytes strongly inhibit axonal regeneration via a neuronal membrane protein Nogo-66 receptor (NgR) (Chen et al., 2000; GrandPre et al., 2000; Fournier et al., 2003). At least three particular proteins expressed by oligodendrocytes have been shown to inhibit axonal

\footnotetext{
Received 0ct. 5, 2006; revised March 6, 2007; accepted March 12, 2007.

We thank Ya Ren and John Dill for technical assistance, and Dr. Martin Schwartz (University of Virginia, Charlottesville, VA) for providing GST-RBD and (3 plasmids.

Correspondence should be addressed to Shuxin Li, Department of Neurology, University of Texas Southwestern Medical Center at Dallas, 5323 Harry Hines Boulevard, Dallas, TX 75390-8813. E-mail: shuxin.li@utsouthwestern.edu.

DOI:10.1523/JNEUROSCI.4353-06.2007

Copyright $\odot 2007$ Society for Neuroscience $\quad$ 0270-6474/07/274154-11\$15.00/0
}

extension, including myelin-associated glycoprotein, oligodendrocyte-myelin glycoprotein, and Nogo (Liu et al., 2002; Wang et al., 2002a; McGee and Strittmatter, 2003). These molecules inhibit axonal extension by binding to the GPI (glycosylphosphatidylinositol)-linked membrane protein NgR. $\mathrm{NgR}$ signal is then transduced via coreceptor complex, lowaffinity neurotrophin receptor p75/Lingo1, or TROY/Lingo1 (Wang et al., 2002b; Mi et al., 2004; Park et al., 2005; Shao et al., 2005). Moreover, several axon-guidance molecules during development, such as semaphorin 5A and Ephrin-3B/Eph-A4, may limit the axonal elongation in the injured CNS (Goldberg et al., 2004; Goldshmit et al., 2004; Benson et al., 2005).

Blocking one of the above inhibitory proteins has induced a degree of axonal regeneration (Schnell and Schwab, 1990; Bradbury et al., 2002; GrandPre et al., 2002; Goldshmit et al., 2004). Interestingly, most of these axon growth-suppressing proteins are intracellularly mediated via activation of a small GTP-binding protein RhoA, a signaling protein regulating neuronal morphogenesis via interaction with other molecules including serine/ threonine kinases, tyrosine kinases, lipid kinases, lipases, oxidases, and scaffold proteins. Particularly, the activated form of Rho (GTP-bound) can bind to Rho kinase (ROCK) and function as the direct activator of ROCK. Activation of ROCK leads to the phosphorylation of various target proteins including myosin light chain, and then mediates the cytoskeletal rearrangements in neurons. Thus, an alternative strategy to overcome the growth inhibitions from multiple extracellular factors is to influence their common downstream pathway including the convergent 
RhoA signal. Indeed, suppressing RhoA or ROCK with pharmacological inhibitors has stimulated axonal growth (Bertrand et al., 2005) and improved behavioral recovery after spinal cord lesion in rodents (Dergham et al., 2002; Fournier et al., 2003). Regulating intracellular signals by enhancing intracellular cAMP levels or inhibiting protein kinase $\mathrm{C}$ has also led to a significant axonal sprouting in the lesioned CNS (Neumann et al., 2002; Qiu et al., 2002; Pearse et al., 2004; Sivasankaran et al., 2004).

Nonsteroidal anti-inflammatory drugs (NSAIDs) are a group of drugs widely used as cyclooxygenase (COX) selective and nonselective inhibitors. Recently, NSAIDs ibuprofen, indomethacin, and sulindac sulfide have been found to reduce the formation of amyloid- $\beta 42$ (Weggen et al., 2001), a critical peptide leading to pathogenic cascade in Alzheimer's disease, via RhoA inactivation (Zhou et al., 2003). These studies suggest the Rho suppression effect of a subset of NSAIDs independent of COX-inhibiting action. Interestingly, treatments with indomethacin, alone or combined with other agents, have been shown to have beneficial effects to animals with spinal cord lesions. Particularly, administration of this agent could reduce the tissue edema and histopathological damage of injured spinal cord and enhance the signal conduction and locomotion recovery of SCI rodents (Simpson et al., 1991; Winkler et al., 1993; Guth et al., 1994a,b). So far, it remains unclear whether the Rho-inhibiting property of indomethacin contributes to its beneficial effects on SCI rodents. In this report, we focus on the Rho-inhibiting property of NSAIDs independent of COX action and explore whether some NSAIDs can overcome the axon growth-inhibiting nature of CNS myelin and CSPGs and promote neuronal regeneration after a CNS injury via suppressing RhoA signal. We found that ibuprofen and indomethacin completely reversed the RhoA activation of neurons induced by CNS myelin, CSPGs, or spinal cord lesion, and stimulated the significant neurite growth in vitro and axonal regeneration in vivo.

\section{Materials and Methods}

Neuronal cultures and neurite outgrowth assay of dorsal root ganglia. Pheochromocytoma (PC12) cells were grown on collagen-coated dishes in DMEM supplemented with $5 \%$ fetal bovine serum and $10 \%$ horse serum, $100 \mu \mathrm{g} / \mathrm{ml}$ penicillin and $100 \mu \mathrm{g} / \mathrm{ml}$ streptomycin, and $2 \mathrm{~mm}$ glutamine. These cells were differentiated for $24 \mathrm{~h}$ with nerve growth factor (NGF) $(100 \mathrm{ng} / \mathrm{ml})$ in DMEM supplemented with $1 \%$ horse serum. Dorsal root ganglia (DRGs) were dissected out from C57BL/6 mice aged 4-6 weeks (Bonilla et al., 2002). After incubation with collagenase and 0.25\% trypsin/EDTA, the dissociated cells were preplated on tissue culture plastic dishes for $1 \mathrm{~h}$ at $37^{\circ} \mathrm{C}$ to eliminate non-neuronal cells. Neurons were plated into four-well chamber slide and grown in culture medium (F12 plus $10 \%$ fetal bovine serum, $1 \%$ glutamine, $1 \%$ penicillin-streptomycin supplied by $100 \mathrm{ng} / \mathrm{ml} \mathrm{NGF}$ ) for $24 \mathrm{~h}$ at $37^{\circ} \mathrm{C}$. In some cases, chamber slides were coated with CNS myelin $(50 \mu \mathrm{g} / \mathrm{ml})$ purified from bovine brain white matter or CSPG $(1.5 \mu \mathrm{g} / \mathrm{ml}$; Millipore, Temecula, CA). The dissociated neurons were treated with vehicles, naproxen $(400 \mu \mathrm{M})$, ibuprofen $(200-600 \mu \mathrm{M})$, and indomethacin $(3 \mu \mathrm{M})$ started $4 \mathrm{~h}$ after cell plating. For neurite outgrowth, DRG cells were fixed $24 \mathrm{~h}$ after plating and stained with rhodamine phalloidin (Invitrogen, San Diego, CA). Images of each culture were captured with a Nikon (Tokyo, Japan) image-collecting system and neurite outgrowth was quantified with NIH Image software (GrandPre et al., 2002). For outgrowth quantification, the total neurite length for each neuron was determined from 30-50 representative neurons in each experiment, and the mean values were calculated from four to six separate experiments.

RhoA activity assay. The levels of GTP-bound RhoA in cultured PC12 neurons or injured spinal cord were measured by precipitation with glutathione $S$-transferase (GST)-rhotekin binding domain (RBD) (Ren et al., 1999; Dubreuil et al., 2003). After 24 h growth in NGF medium,
PC12 cells were incubated with NSAIDs or Rho inhibitors for $30 \mathrm{~min}$, and then stimulated with 15 min lysophosphatidic acid (LPA) $(15 \mu \mathrm{M} ; 1 \mathrm{~h}$ starvation in serum-free medium before drug treatments), purified CNS myelin $(50 \mu \mathrm{g} / \mathrm{ml})$, or CSPG $(1.5 \mu \mathrm{g} / \mathrm{ml})$. After washing with ice-cold PBS, cells were prepared in $1 \mathrm{ml}$ of cold lysis buffer supplemented with protease inhibitors ( $1 \mathrm{~mm}$ phenylmethylsulfonyl fluoride, $2 \mathrm{~mm}$ orthovanadate, $10 \mu \mathrm{g} / \mathrm{ml}$ leupeptin, and $10 \mu \mathrm{g} / \mathrm{ml}$ aprotinin) and clarified by centrifugation at $15,000 \times g$ for $5 \mathrm{~min}$ at $4^{\circ} \mathrm{C}$. After total protein quantification in lysates with Bio-Rad (Hercules, CA) DC protein assay reagents, samples containing the same amount of protein were incubated with RBD-coupled beads ( $45 \mu \mathrm{g} /$ sample; Cytoskeleton, Denver, CO) for $50 \mathrm{~min}$ at $4^{\circ} \mathrm{C}$. GTP-bound RhoA and total RhoA in the cell lysates were detected by Western blot using a mouse monoclonal antibody against RhoA (sc-418; Santa Cruz Biotechnology, Santa Cruz, CA) (Ren et al., 1999; Dubreuil et al., 2003). Proteins were transferred to nitrocellulose membrane and bands were visualized with enhanced chemiluminescence reagents (Amersham Biosciences, Piscataway, NJ). For RhoA activity in the lesioned spinal cord, a moderate contusion injury was performed in adult female rats at T9 level. Three hours after injury, NSAID naproxen $\left(50 \mathrm{mg} \cdot \mathrm{kg}^{-1} \cdot \mathrm{d}^{-1}\right)$, ibuprofen $\left(60 \mathrm{mg} \cdot \mathrm{kg}^{-1} \cdot \mathrm{d}^{-1}\right)$, or a vehicle was administered with daily subcutaneous injections. Five days after injury, rats were perfused through heart with cold PBS for $10 \mathrm{~min}$ and fresh spinal cord tissue $5 \mathrm{~mm}$ rostral to and caudal to lesion center (10 mm long) was collected and prepared in $1 \mathrm{ml}$ of lysis buffer with protease inhibitors for RhoA activity assay. For blot densitometry assay, the images of active RhoA bands were captured with a Bio-Rad Gel Doc $\mathrm{XR}$ documentation system, and the band density was determined using Quantity One software.

To visualize active RhoA signal in individual cells, we conducted the GST-RBD binding assay in fixed DRG neurons and rat spinal cord $7 \mathrm{~d}$ after a contusion injury at T9 $(5 \mathrm{~mm}$ rostral or caudal to SCI; $10-40 \mu \mathrm{m}$ thick) (Dergham et al., 2002; Madura et al., 2004). Cultured DRGs or parasagittal tissue sections were incubated with clarified lysate prepared from bacteria expressing GST-RBD overnight. After blocking in 3\% BSA, cells or sections were incubated with anti-GST antibody (Invitrogen) to detect RBD-bound Rho-GTP. To localize Rho-GTP to the definite cells, the cell type-specific antibodies [NeuN, neurons; neurofilament, axon cylinders; GFAP, astrocytes; adenomatous polyposis coli (APC), oligodendrocytes] were applied in some sections. The levels of active RhoA in cultured DRGs were determined by measuring the RBD-bound signal in neuronal bodies and neurites with MetaVue software. The active RhoA signal in each neuron was calculated from 15 to 25 representative neurons (five to six images) in each group.

Spinal cord lesions and axonal tracing. In SCI models, female Sprague Dawley rats (weight, 180-250 g) were deeply anesthetized with ketamine $(70 \mathrm{mg} / \mathrm{kg})$ and xylazine $(8 \mathrm{mg} / \mathrm{kg})$. For dorsal over-transection, laminectomy was conducted and spinal cord was exposed at spinal levels of T6-T7. The dorsal part of the cord was cut with a pair of microscissors to sever the dorsal parts of corticospinal tracts. The depth of lesion $(\sim 1.9$ $\mathrm{mm}$ ) was assured by passing the sharp part of no. 11 blade across the dorsal spinal cord. This model typically transects all of the dorsal, dorsolateral, and lateral corticospinal tract (CST) fibers, but spares some of ventral CST ( $\mathrm{Li}$ et al., 2004). A total of 46 rats underwent the transection injury procedure, 15 receiving vehicle, 15 receiving naproxen, and 16 receiving ibuprofen. During the first $8 \mathrm{~d}$ after spinal cord injury, four rats died in each of saline and naproxen groups and two rats died in inbuprofen group because of the poor general health. Two rats were killed in the naproxen group 5 weeks after transection injury because of ongoing mutilation of one foot. In addition, seven rats (three, two, and two rats in three groups, respectively) were excluded from the anatomical and behavioral analysis because of an incomplete lesion documented by two to four uninjured dorsal CST fibers in the distal transverse spinal cord sections. One more rat in the saline group was excluded from the study because of a low CST tracing efficacy verified from the transverse rostral spinal cord sections at 6 weeks after injury. Thus, 7 vehicle-, 7 naproxen-, and 12 ibuprofen-treated animals completed the study and were used for axonal quantification and behavioral analysis in the overhemitransection injury model. For contusion SCI, the laminectomy was performed at T8-T9, and a moderate lesion was made with NYU Impac- 
tor. A total of 16 rats were used for contusion injury procedure, 8 in each of the vehicle and ibuprofen groups. One rat in the each group was killed during the first week after SCI because of poor general health. One more rat was excluded from the study in each group because of a verified minipump crack during tissue dissection 6 weeks after SCI. Thus, six animals in each group were used for anatomical and behavioral analysis in the contusion injury model.

An osmotic mini-pump (2ML4; Alzet, Cupertino, CA; $2 \mathrm{ml}$ volume for $28 \mathrm{~d}$ ) was used to infuse ibuprofen $\left(60 \mathrm{mg} \cdot \mathrm{kg}^{-1} \cdot \mathrm{d}^{-1}\right)$, naproxen $\left(50 \mathrm{mg} \cdot \mathrm{kg}^{-1} \cdot \mathrm{d}^{-1}\right)$, or saline subcutaneously. Treatments were initiated immediately after a transection or $7 \mathrm{~d}$ after a contusion SCI. Four weeks after lesion, burr holes were made on each side of the skull overlying sensorimotor cortex of lower limbs. Tracer biotin dextran amine (BDA) (molecular weight, 10,$000 ; 10 \%$ in PBS; $3.5 \mu \mathrm{l} /$ cortex) was applied at seven injection sites at a depth of $1.5 \mathrm{~mm}$ from cortical surface on each side. Two weeks after BDA injections, the animals were killed by perfusion with cold PBS, followed by $4 \%$ paraformaldehyde. The spinal cord was dissected and postfixed overnight in the same fixative.

For Rho-GTP assay, some rats with a contusion injury were perfused 5-7 $\mathrm{d}$ after SCI.

Histology. The rat spinal cord tissue 7-10 $\mathrm{mm}$ rostral to and 7-10 mm caudal to the lesion site (14-20 mm long, containing lesion area) was cut parasagittally on a vibratome. Transverse sections were collected from the spinal cord $8-16 \mathrm{~mm}$ rostral to and $8-16 \mathrm{~mm}$ caudal to the injury site. After $1 \mathrm{~h}$ preincubation with $0.5 \%$ BSA, $0.5 \%$ Triton in Tris-buffered saline, sections were incubated with avidin-biotin-peroxidase complex in Tris-buffered saline with $0.1 \%$ bovine serum albumin, $0.3 \%$ Triton for 3-4 d at room temperature. The BDA tracer was visualized by nickelenhanced diaminobenzidine HRP reaction. To visualize serotonergic fibers and lesion area, all of the sagittal sections and some transverse sections were double stained with antibody against 5-HT and astrocytic marker GFAP. The microscopic slices were pasted on glass slides and analyzed with a Nikon microscope. For CST fiber quantification in the sagittal sections, the BDA-labeled fibers $\geq 200 \mu \mathrm{m}$ in sprouting diameter outside of ventral CST were counted at various distances caudal to the injury from all of the sagittal sections of each rat. For CST fiber quantification from transverse sections in the rats with transection SCI, the averaged number of BDA-labeled axons was obtained from four random sections at $7-10$ or $11-15 \mathrm{~mm}$ distal to the lesion site in each animal. To determine serotonergic fibers at the spinal cord 11-15 mm distal to the lesion site, the individual fibers stained by 5 -HT antibody in the ventral and dorsal halves of spinal cord were traced, and the mean density of traced 5-HT fibers was calculated from two random transverse sections in each rat using NIH software. Throughout the surgery, postoperative care and histological analysis, researchers were blind to the identity of compounds in the minipumps.

Behavioral tests. Basso, Beattie, and Bresnahan (BBB) locomotor scale, grid walking, and footprint analysis were used to evaluate functional recovery. For grid walking, the rats were trained to walk on a wire grid (90 $\mathrm{cm}$ long; $25 \mathrm{~mm}$ between grids) before surgery. Six weeks after injury, the grid walk was videotaped and the number of instances in which the hindpaw dropped below the grid plane was counted. For footprint analysis, the walking patterns of hindpaws were recorded with ink during a continuous locomotion across a $90 \mathrm{~cm}$ runway. The stride length on each side and stride width between two sides were calculated (Metz et al., 2000b; Li et al., 2004).

In this study, the statistical analyses were performed using two-tailed Student's $t$ test. The differences with $p<0.05$ were considered significant between the control and drug groups.

\section{Results}

Ibuprofen and indomethacin inactivate RhoA in cultured neurons exposed to axon growth inhibitors

NSAIDs ibuprofen, indomethacin, and sulindac sulfide have been shown to suppress isoprenoid-induced RhoA activity in cultured neuroblastoma cells (Zhou et al., 2003). To test whether such NSAIDs can silence neuronal RhoA activation induced by Rho agonist or axon growth inhibitors, we examined levels of active RhoA in cultured neuron-like PC12 cells or DRG neurons using two approaches. We first measured amounts of active RhoA in the lysates of PC12 cells by precipitation with RBD that only binds GTP-bound form of RhoA (Ren et al., 1999; Dubreuil et al., 2003). LPA, a RhoA agonist by binding to LPA receptor, dramatically increased the active RhoA levels in P12 cells 15 min after exposure. Incubations with ibuprofen $(500 \mu \mathrm{M})$ or indomethacin $(5 \mu \mathrm{M})$ mostly prevented the LPA-induced RhoA activation, but not treatment with NSAID naproxen $(400 \mu \mathrm{M})$ (Fig. $1 A, B)$. Notably, the same concentration of ibuprofen has been shown effectively to suppress Rho activity in neuroblastoma cultures (Zhou et al., 2003). More importantly, PC12 cells exposed to purified CNS myelin $(50 \mu \mathrm{g} / \mathrm{ml})$ or CSPG $(1.5 \mu \mathrm{g} / \mathrm{ml})$, two potent inhibitory substrates to CNS neuronal growth, display higher endogenous Rho-GTP levels than those on PBS controls (Fig. $1 C-F$ ). But activation of RhoA by these inhibitory substrates was completely reversed by treatments with ibuprofen $(500 \mu \mathrm{M})$, indomethacin $(5 \mu \mathrm{M})$, or Rho inhibitor C3 transferase $(4 \mu \mathrm{g} / \mathrm{ml})$, not with naproxen $(400 \mu \mathrm{M})$. To confirm the RhoA-inhibiting effect of NSAIDs in neuronal cultures, we incubated fixed cultured mouse DRG neurons with GST-RBD and examined the RBD-bound neurons with anti-GST antibody $24 \mathrm{~h}$ after cell plating (Dubreuil et al., 2003). Staining signal for Rho-GTP is dramatically enhanced by $30 \mathrm{~min}$ incubation with CNS myelin or CSPG substrates compared with PBS controls (Fig. 2). Treatments with C3 transferase, ibuprofen, or indomethacin reversed the increased Rho-GTP in the cell bodies and neurites of DRG neurons. These results support that CNS myelin and CSPG substrates activate intracellular RhoA signal of neurons, but ibupro- 
A

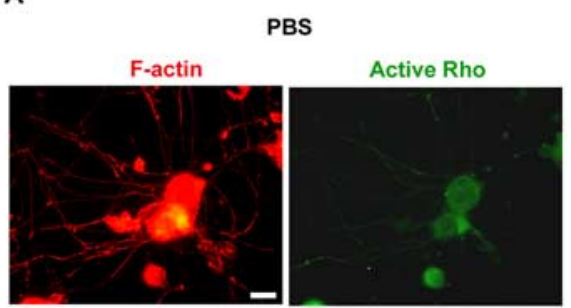

B

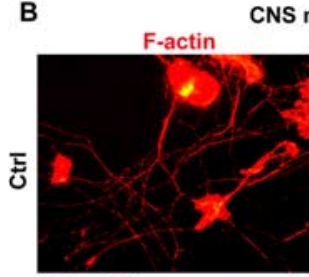

CNS myelin
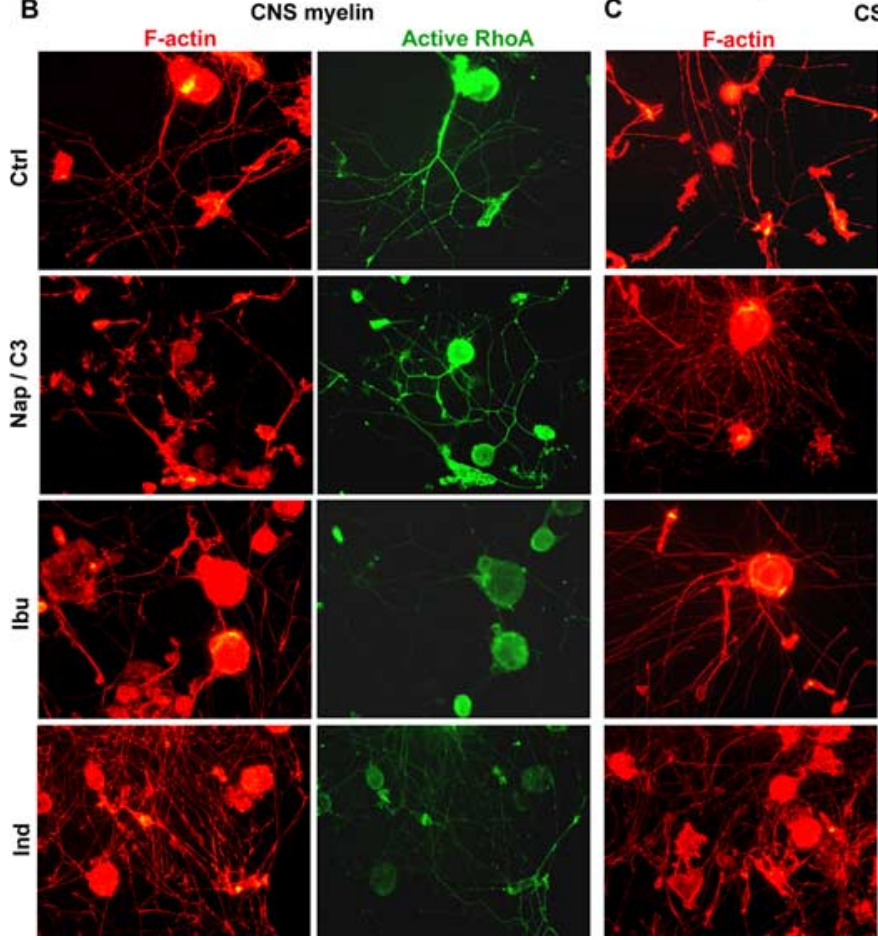

CSPG
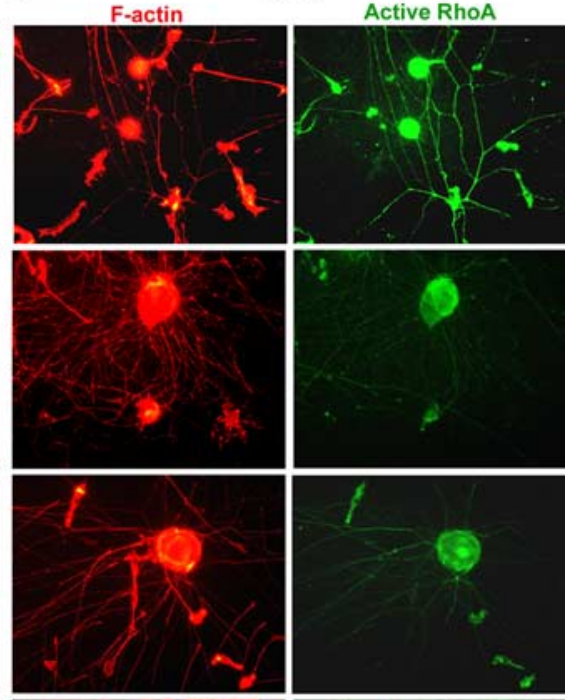

Figure 2. Ibuprofen and indomethacin reduce Rho-GTP signal in DRG neurons on inhibitory substrates. $\boldsymbol{A}$, The active RhoA signal (green) in fixed mouse DRG cultures was detected by GST-RBD binding and immunostaining without any inhibitory substrates and NSAID treatments. F-actin staining with rhodamine phalloidin (red) outlines the neuronal structure. $\boldsymbol{B}, \boldsymbol{C}$, The active RhoA signal in DRG neurons was increased $30 \mathrm{~min}$ after exposure to CNS myelin $(50 \mu \mathrm{g} / \mathrm{ml})$ or CSPG substrates $(1.5 \mu \mathrm{g} / \mathrm{ml})$. Pretreatments with C3 (right two panels), ibuprofen, or indomethacin dramatically reversed the increased active RhoA induced by myelin or CSPG, but not pretreatment with naproxen (left two panels). Scale bar, $20 \mu \mathrm{m}$. D, Bar graph indicates the active RhoA signal in DRG cultures by measuring levels of RBD-bound reactivity in neuronal bodies and neurites. The active RhoA in each neuron was calculated from $15-25$ representative neurons in each group. The means \pm SEM are reported ( $n=5-6$ images/group). The differences indicated are compared with myelin or CSPG control ( ${ }^{*} p<0.05$, Student's $t$ test). Nap, Naproxen; Ibu, ibuprofen; Ind, indomethacin; Mye, myelin.

fen and indomethacin have the capacity to reverse the RhoA activation induced by axon growth inhibitors in vitro.

\section{RhoA-inhibiting NSAIDs enhance neurite growth of DRG neurons on inhibitory substrates}

RhoA activation has been shown to play a key role in limiting axonal extension in the CNS neurons (Dergham et al., 2002; Fournier et al., 2003). To determine whether RhoA inactivation with NSAIDs can overcome axon growth restrictions from CNS myelin or CSPGs, we assessed the effects of RhoA-inhibiting ibuprofen and indomethacin on neurite outgrowth of mouse DRG neurons exposed to these substrates (Fig. 3). Both CNS myelin and CSPG dramatically reduce the neurite number and length in the isolated DRG cultures. Application of ibuprofen or indomethacin dramatically recovers the outgrowth of DRG neurons exposed to the inhibitory substrates. Notably, non-RhoA-inhibiting NSAID naproxen does not have a similar role in DRG growth, demonstrat- ing that growth-promoting effect of ibuprofen and indomethacin is most likely dependent on RhoA suppression. The potency of ibuprofen in reversing myelin inhibition is characterized below $600 \mu \mathrm{M}$ (Fig. 3C). The growth-promoting efficiency of ibuprofen is similar to that of Rho inhibitor C3 transferase $(4 \mu \mathrm{g} / \mathrm{ml})$ or Rho kinase inhibitor $(R)-(+)$-trans- $N$-(4-pyridyl)-4(1-aminoethyl)-cyclohexanecarboxamide (Y27632) (10 $\mu \mathrm{M})$. A lesser degree of recovery after RhoA inhibition with indomethacin is possibly attributable to the toxic effect of methanol in which this drug was dissolved. Myelin or CSPG inhibition of axon growth is not completely blocked by RhoA inactivation with NSAIDs, C3, or Y27632. The unrecovered axon growth inhibition by CNS myelin or CSPG may be attributable to the RhoA-independent signaling pathway that regulates axonal extension (Fournier et al., 2003). Together, these experiments suggest that some NSAIDs are able to overcome the growth restrictions of two types of major inhibitors in the CNS.

\section{Ibuprofen reverses RhoA activation in the lesioned rat spinal cord in vivo}

After a trauma in the CNS, injured neurons are exposed to various axonal growth inhibitors including CNS myelin and CSPGs, which should activate intracellular RhoA signal around lesion. To determine whether NSAIDs can restrain active RhoA in the lesioned CNS in vivo, we delivered naproxen $\left(50 \mathrm{mg} \cdot \mathrm{kg}^{-1} \cdot \mathrm{d}^{-1}\right)$, ibuprofen $\left(60 \mathrm{mg} \cdot \mathrm{kg}^{-1} \cdot \mathrm{d}^{-1}\right)$ subcutaneously to rats with a moderate contusion spinal cord lesion at T9. The doses of NSAIDs used here are higher than those in the clinics $\left(\sim 15 \mathrm{mg} \cdot \mathrm{kg}^{-1} \cdot \mathrm{d}^{-1}\right)$ when administered as COX inhibitors. The high doses of ibuprofen at 50-62.5 $\mathrm{mg} \cdot \mathrm{kg}^{-1} \cdot \mathrm{d}^{-1}$ have been shown effectively to reduce amyloid- $\beta 42$ formation (Weggen et al., 2001; Eriksen et al., 2003; Yan et al., 2003; Zhou et al., 2003), likely via RhoA-inhibiting action (Zhou et al., 2003). No overt side effects were reported in rodents treated with the indicated high doses (Weggen et al., 2001). Consistent with the previous report (Dubreuil et al., 2003), active RhoA signal was remarkably increased compared with non-SCI controls $5 \mathrm{~d}$ after injury (Fig. 4A,B). Treatments with systemic ibuprofen (60 $\left.\mathrm{mg} \cdot \mathrm{kg}^{-1} \cdot \mathrm{d}^{-1}\right)$, but not with naproxen, completely prevent the RhoA activation in the lesioned spinal cord, although total RhoA levels are similar among different animals. This result is consistent with our observations from the in vitro studies (Figs. 1, 2) and the previous report in neuroblastoma cells (Zhou et al., 2003). To confirm the RhoA-inhibiting effect of NSAID in individual cells, we detected Rho-GTP signal in fixed spinal cord sections via GST-RBD binding and immunostaining against GST (Fig. 4C-E). The basic staining for active RhoA is low in noninjured spinal cord. We observed many positive RBD-binding cells 
a few millimeters from the lesion epicenter $7 \mathrm{~d}$ after SCI. Double staining with cellular markers (neurofilament for axons and APC for oligodendrocytes) indicates the high Rho-GTP signal in axon cylinders and glia in white matter (data not shown). More importantly, administration of ibuprofen almost completely reversed the active RhoA signal in the lesioned spinal cord, suggesting that systemic treatment with ibuprofen suppresses RhoA activity in the injured CNS in vivo.

Ibuprofen promotes corticospinal and serotonergic axonal growth in rat spinal cord with dorsal hemisection

To the extent that RhoA activation is responsible for restricting axonal regrowth in vivo after a CNS injury, RhoA inhibition with NSAIDs should stimulate regeneration after a CNS axotomy. We tested this hypothesis using two in vivo SCI models for the following reasons. Dorsal spinal cord transection interrupts a group of defined pathways and spares ventral fiber tracts, which provide a tissue bridge for regenerating axons. Thus, this model is widely used for studying the regenerationrelated behavioral alterations (Huang et al., 1999; GrandPre et al., 2002; Rosenzweig and McDonald, 2004). Given that transection lesion is different from the spinal cord injuries in most SCI patients, we also tested the Rho-inhibiting NSAIDs using the second SCI model of contusion in this study. The contusion model produces a lesion that resembles the complex lesions of many SCI patients (Metz et al., 2000a), including the dramatic central gray matter necrosis with variable white matter damage. First, we examine the effects of RhoAinhibiting ibuprofen on descending axonal growth by delivering NSAIDs or vehicle to rats with a midthoracic overtransection injury in dorsal spinal cord (Fig. $5 A$, inset). Ibuprofen $(60 \mathrm{mg} \cdot \mathrm{kg}$ body weight $\left.{ }^{-1} \cdot \mathrm{d}^{-1}\right)$, naproxen $(50$ $\left.\mathrm{mg} \cdot \mathrm{kg}^{-1} \cdot \mathrm{d}^{-1}\right)$, and vehicle were initiated immediately after transection injury via subcutaneous injection using osmotic minipumps for 4 weeks. These doses produced no evidence of overt toxicity to animals (Weggen et al., 2001). The integrity of descending CSTs on both sides was traced by injecting BDA into the motor cortex. After lesion in controls (GrandPre et al., 2002; Li et al., 2004), the prominent dorsal, dorsolateral, and lateral CST fibers are disrupted and only partial ventral CST axons are detectable in caudal spinal cord by BDA labeling (Fig. 5A). No obvious CST sprouts are seen in either rostral or distal spinal cord. In contrast, in ibuprofen-treated rats, camera lucida drawings of CST fibers from all sagittal sections of each rat indicate numerous CST fiber sprouts rostral to lesion and many BDA-labeled fibers outside of ventral CST in the dorsal part of caudal spinal cord (Fig. 5C) (Li et al., 2004). Photomicrographs of CST fibers a few millimeters distal to the transection site ${ }^{* *} p<0.01$, Student's $t$ test).
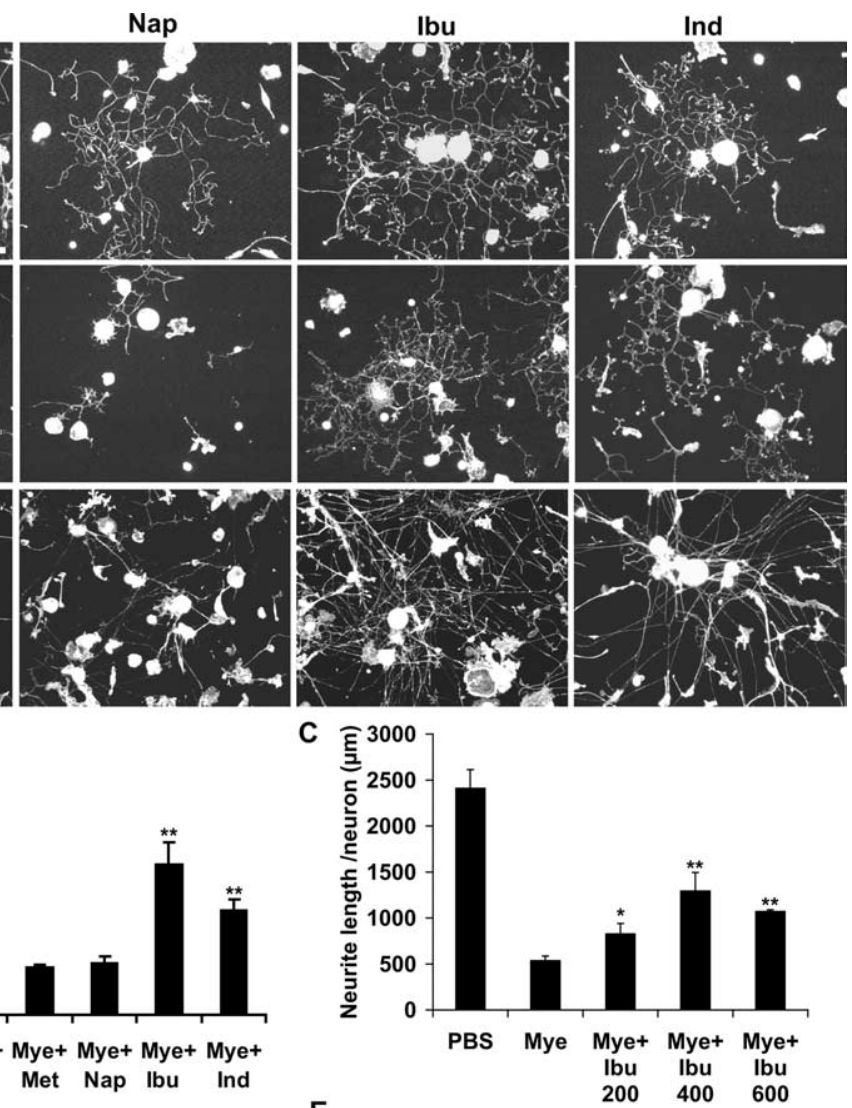

E

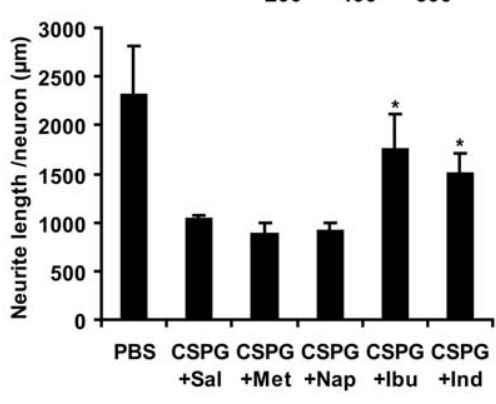

Figure 3. Ibuprofen and indomethacin promote neurite outgrowth of cultured DRG neurons on CNS myelin or CSPG substrates. A, Dissociated DRG neurons from 4-6 week mice were treated with naproxen (Nap) (400 $\mu \mathrm{M}$ ), ibuprofen (Ibu) (400 $\mu \mathrm{M}$ ), or myelin (Mye) $(50 \mu \mathrm{g} / \mathrm{ml})$, or CSPG $(1.5 \mu \mathrm{g} / \mathrm{ml})$ substrates. $\boldsymbol{B}-\boldsymbol{E}$, The neurite outgrowth per DRG neuron was quantified $24 \mathrm{~h}$ after

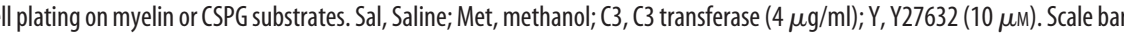
$50 \mu \mathrm{m}$. The numbers in bar graphs indicate means \pm SEM from four to six separate experiments ( $30-50$ representative neurons were analyzed for each experiment). The differences indicated are compared with the vehicle-matched controls ( ${ }^{*} p<0.05$,

reveal many tortuous branched CST sprouts in the ibuprofen rats (Fig. $5 D, E$ ). Counts of CST fibers $\geq 200 \mu \mathrm{m}$ in sprout diameter from sagittal sections document a much greater number of CST axons in ibuprofen rats than in controls or naproxen animals (Fig. 5F). Moreover, more BDA-labeled CST axons are observed in transverse sections of spinal cord 7-10 mm caudal to the lesion (Fig. 5G), particularly in the dorsal part of spinal cord, in the ibuprofen animals. We also observed the trend of augmented CST axons at a lower level of transverse spinal cord sections 11-15 mm distal to SCI in the ibuprofen-treated rats, although the difference between ibuprofen and control groups did not reach statistical significance (data not shown). The difference among three groups cannot be attributed to altered CST tracing efficacy or lesion depth because the general labeling density for predominant dorsal CST above lesion and the lesion depth visual- 


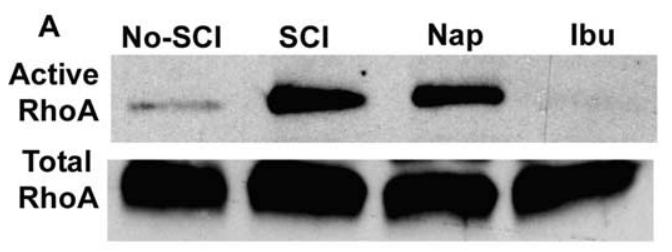

B

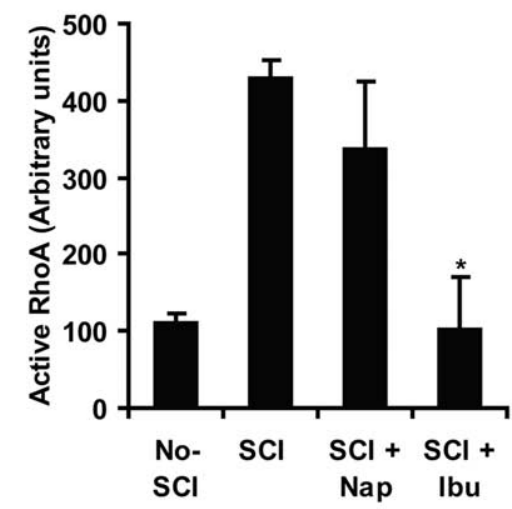

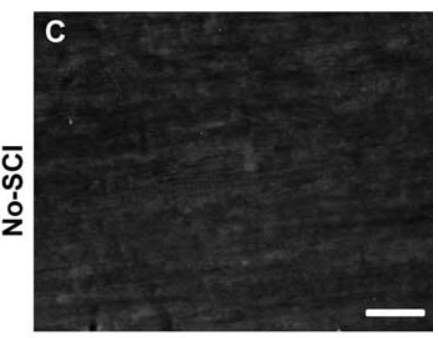
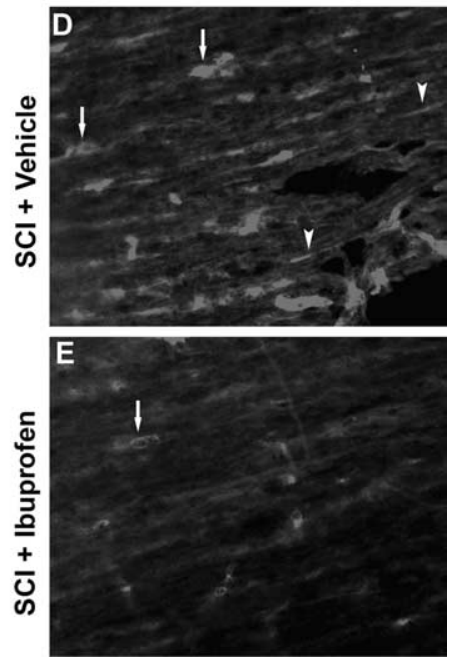

groups display the scarring and a large cavity in the lesion epicenter surrounded by numerous small cavitations (Fig. $6 \mathrm{~A}, \mathrm{C})$. Rostral to the lesion, the linear projected CST axons from the vehicletreated rats terminated at a few hundred micrometers to several millimeters above the lesion (Fig. 6A). In contrast, the similar sections from ibuprofen animals display some of BDA-labeled CST fibers extending into the wall of central cavitation (Fig. 6C). Caudal to the lesion site, very few BDA-labeled CST fibers are present in the control rats, but many BDA-labeled fibers are detectable in the ibuprofentreated animals, particularly in the gray matter area (Fig. $6 C-G$ ). Counts of BDAlabeled fibers $\geq 200 \mu \mathrm{m}$ in sprout diameter from all of the sagittal sections per rat $1-10 \mathrm{~mm}$ caudal to the lesion indicate five times more CST fibers in the ibuprofentreated rats than in the controls ( 190 vs 26 fibers per rat) (Fig. $6 H$ ). In particular, the postponed treatment with ibuprofen increased the BDA-labeled CST axons in the gray matter area of distal spinal cord (Fig. $6 F, H)$. The difference in white matter area is not significant between the saline and ibuprofen groups (Fig. 6G,H). The majority of these fibers do not have the linear trajectory of uninjured fibers but follow the branching and tortuous courses (Fig. 6D,E). These increased caudal CST fibers may derive from the regenerating CST fibers from lesioned axons and/or the sprouting from spared CST axons induced by RhoA inactivation with ibuprofen.

Systemic ibuprofen reverses RhoA activation 5-7 d after a moderate contusion spinal cord injury in rats. $A$, RhoA in spinal cord $5 \mathrm{~mm}$ rostral to and $5 \mathrm{~mm}$ caudal to lesion was detected via GST-RBD binding and immunoblotting with antibody specific to RhoA. Total RhoA from the same tissue samples was detected via immunoblotting (bottom bands; $20 \mu \mathrm{g}$ of protein per lane). Notably, systemic administration of NSAID ibuprofen completely reversed the RhoA activation in the lesioned spinal cord $5 \mathrm{~d}$ after injury. $\boldsymbol{B}$, Densitometric analysis of RhoA activity was indicated in bar graph from three separate experiments (means $\pm \mathrm{SEM} ; n=3 ;{ }^{*} p<0.05$ compared with SCI controls, Student's $t$ test). C, A sagittal section of spinal cord at midthoracic level from uninjured rat reveals the low staining signal for active RhoA via GST-RBD binding and immunostaining. D, E, Parasagittal sections of rat spinal cord $7 \mathrm{~d}$ after a moderate contusion injury $3 \mathrm{~mm}$ rostral to the lesion center display the reactivity for active RhoA in white matter from vehicle $(\boldsymbol{D})$ - or ibuprofen $(\boldsymbol{E})$-treated rats. Notably, RhoA activity was dramatically attenuated in $\mathrm{SCl}$ rats treated with $7 \mathrm{~d}$ systemic ibuprofen at $60 \mathrm{mg} \cdot \mathrm{kg}^{-1} \cdot \mathrm{d}^{-1}$. Scale bar, $50 \mu \mathrm{m}$. Nap, Naproxen; Ibu, ibuprofen.

ized by immunostaining astrocytic marker GFAP are similar in these animals (data not shown). It is plausible that the caudal CST sprouting fibers in ibuprofen-treated rats are derived from spared ventral CST or the growth of axotomized CST fibers into distal spinal cord via bridging tissue in the ventral part (Li et al., 2004, 2005).

The raphespinal system was also examined in some transverse sections in these spinal-injured rats. Immunostaining for 5-HT demonstrates a very high density of serotonergic fibers in the spinal cord rostral to the lesion in vehicle- or NSAID-treated rats. The number of serotonin fibers at the spinal cord 11-15 mm caudal to injury is remarkably reduced in all the SCI rats, but is significantly greater in the ibuprofen-treated rats than that in control or naproxen groups (Fig. $5 H-K$ ). Thus, these data demonstrate that RhoA inactivation with systemic ibuprofen induced significant growth of descending CST and 5-HT fibers in the distal spinal cord after a dorsal over-hemisection injury.

Delayed ibuprofen stimulates descending axonal growth after a contusion SCI in rats

Drug delivery initiated at the time of SCI is logistically difficult for the treatment of most SCI patients. Then, we determine whether administration of ibuprofen at $7 \mathrm{~d}$ delayed time window can stimulate axonal growth of descending fiber tracts after a moderate rat contusion injury. In these rats, the treatment with vehicle or ibuprofen was initiated $7 \mathrm{~d}$ after SCI and persisted for 4 weeks. Six weeks after SCI, parasagittal sections across the lesion in both
Moreover, serotonergic fibers were examined in rostral and caudal spinal cord of contusion SCI rats. Similar to dorsal transection, the contusion injury lesioned most of serotonergic fibers at injury site. Treatment with postponed ibuprofen dramatically increased 5-HT axons in the lumbar spinal cord (Fig. 6I-K), although the lesion areas visualized by GFAP staining are similar in vehicle- or ibuprofen-treated rats (data not shown).

\section{Treatment with ibuprofen improves the locomotion recovery} of SCI rats

The anatomical analyses display the dramatic axonal growth of motor tracts after RhoA inhibition with systematic ibuprofen. A related key issue is whether ibuprofen treatments benefit functional recovery. Thus, we evaluated the behavioral recovery in these rats in a blind manner. A standardized rat locomotor scoring system was used to assess the outcome (Basso et al., 1995; GrandPre et al., 2002). Two days after an over-hemisection injury, the rats typically show no observable movement or slightextensive movement of one joint (BBB, 0-2) (Fig. 7A). Several weeks after injury, the control rats exhibit partial recovery probably because of the reorganization of segmental circuitry and the short-range sprouting from the spared fibers. The recovery reaches a stable level by 3-4 weeks after SCI. Generally, by 4-6 weeks after SCI, the control rats have consistent weightsupported plantar steps, frequent or consistent forelimb-hindlimb coordination, but rotate the predominant paw position 
when making the initial contact with a testing surface. BBB score in naproxen rats appeared to have a slightly better recovery than controls 1 week post-SCI, but returned to the SCI control level 4-6 weeks after injury. This may relate to the antiinflammatory effect of naproxen. In contrast, the locomotor score in the rats with ibuprofen treatment initiated at the time of injury continues to increase $4-6$ weeks after lesion, and most of them have the consistent forelimb-hindlimb coordination plus the parallel paw position at initial contact with testing surface.

To further characterize the locomotion recovery, two more tests were performed in these rats. In the second test, rats walked on a runway covered with a metal grid (25 $\mathrm{mm}$ between grids) and excursions of hindlimbs below the grid plane were counted from videotaping (Metz et al., 2000b). Uninjured rats make no errors on this test. Six weeks after injury, the control rats made numerous errors by misplacing their hindpaws and falling into grid holes (65\%), but the rats treated with ibuprofen made fewer errors $(45 \%)$ by correctly placing hindpaws on the grid (Fig. $7 B$ ). Analysis of hindpaw footprints displays the decreased stride length and increased stance width in the saline-treated rats 6 weeks after SCI. But treatment with ibuprofen significantly recovered the stride length and width (Fig. 7C,D). Notably, the locomotor $\mathrm{BBB}$ score in the delayed ibuprofen-treated rats continues to increase $4-6$ weeks after a contusion injury, and these rats also performed better on the grid walk task by making fewer errors 6 weeks post-SCI (Fig. 7E,F). Thus, these data indicate that treatments with the NSAID ibuprofen, whether initiated at the time of SCI or with a 1 week delay, significantly improve the behavioral recovery in the adult rodents with SCI.

\section{Discussion}

The treatments for patients suffering from CNS axonal injury are currently very limited because of the complicated injury mechanisms and the neuronal growth failure. The only approved drug for SCI is methylprednisolone, an acute therapy administered only shortly after trauma via neuroprotection (Bracken et al., 1997). The major findings of this study are the identification of NSAIDs ibuprofen and indomethacin overcoming neuronal growth inhibitions from CNS myelin and CSPGs via repressing the activity of intracellular RhoA signal. More importantly, the ability of ibuprofen to attenuate CNS myelin and CSPG inhibitions of axonal growth stimulates a significant axonal sprouting of descending fiber tracts in the distal spinal cord after a transection or a contusion injury. Accordingly, ibuprofen promotes a remarkable locomotor functional recovery, even when delivered 1 week after trauma. The axon growth-promoting effect and the
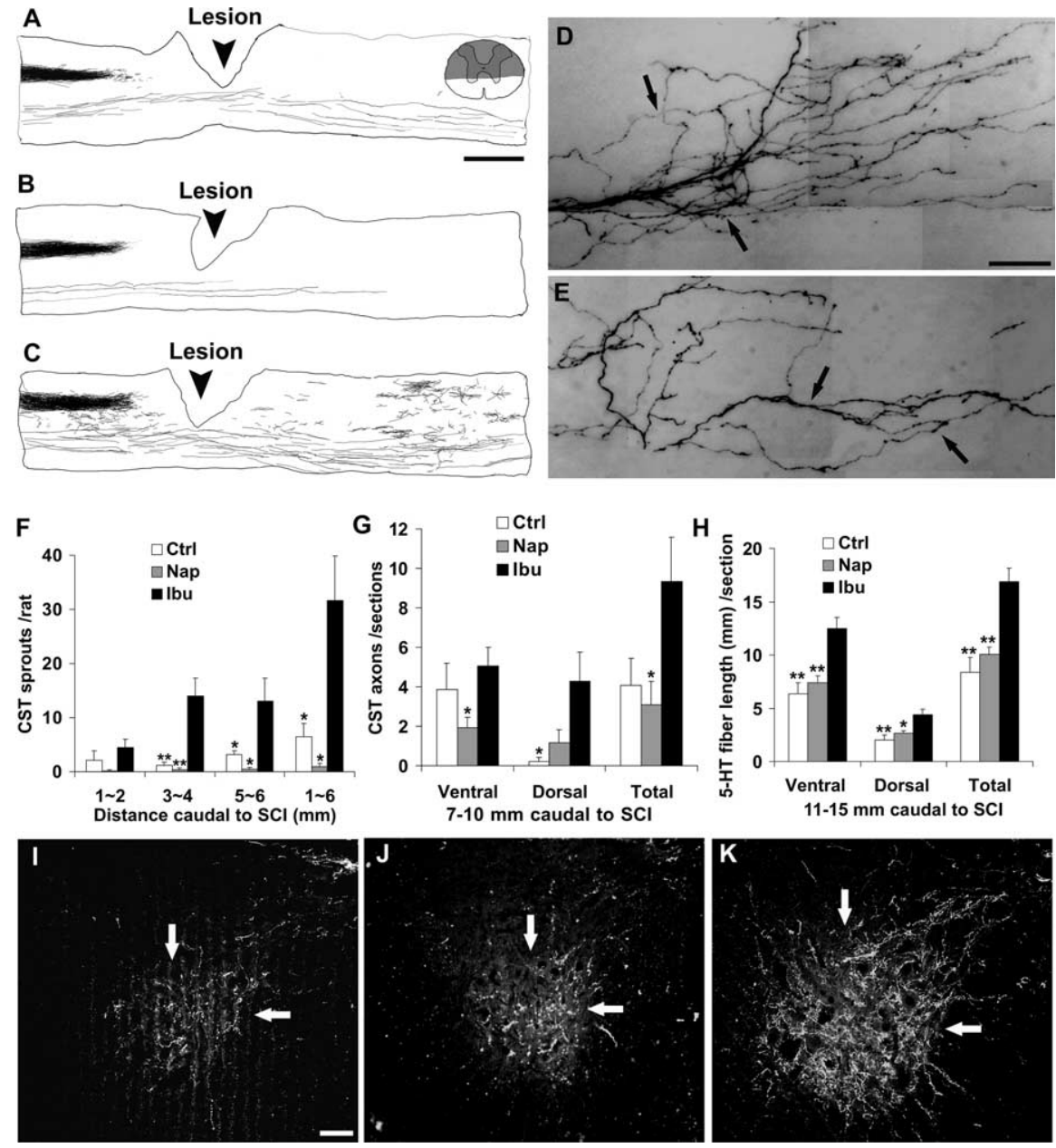

Figure 5. Systemic ibuprofen promotes corticospinal and serotonergic axonal growth caudal to a midthoracic dorsal overhemisection in rats. $\boldsymbol{A}-\boldsymbol{C}$, Camera lucida drawings of CST fibers from all sagittal sections of each rat are shown from the $\operatorname{control}(\boldsymbol{A})$, naproxen ( $\boldsymbol{B}$ ), and ibuprofen $(\boldsymbol{C}$ animals. The inset in $\boldsymbol{A}$ indicates the transected dorsal spinal cord area (shadowed) in this model. fibers after injury. In contrast, subcutaneous injection of ibuprofen started immediately after SCl $\left(60 \mathrm{mg} \cdot \mathrm{kg}^{-1} \cdot \mathrm{d}^{-1}\right.$ for 4 ws induces a number of CST fiber sprouts in the dorsal part of distal spinal cord, particularly into the gray matter areas. The groups. G, Counting of BDA-labeled CST fibers from transverse sections at 7-10 mm distal to the lesion indicates more BDA-labeled fibers in the ibuprofen group, particularly in the dorsal half of spinal cord. $\boldsymbol{H}$, The serotonin fiber length in the ventral or dorsal half spinal cord sections 11-15 mm distal to the lesion exhibit more 5-HT fibers in the ventral half (arrows) of the spinal cord in buprofen rat $(\boldsymbol{K})$ than in saline $(\boldsymbol{I})$ or naproxen $(\boldsymbol{J})$ rats. Scale bars: $\boldsymbol{A}-\boldsymbol{C}, 1 \mathrm{~mm} ; \boldsymbol{D}, \boldsymbol{E}, 25 \mu \mathrm{m} ; \boldsymbol{I}-\boldsymbol{K}, 50 \mu \mathrm{m}$. Means + SEM are reported. The differences indicated in bar graphs $(\boldsymbol{F}-\boldsymbol{H})$ are compared with the ibuprofen group $(n=7,7,12$ rats in the saline, naproxen, and ibuprofen groups, respectively; ${ }^{*} p<0.05,{ }^{* *} p<0.01$, Student's $t$ test). Nap, Naproxen; Ibu, ibuprofen.

common use of ibuprofen in patients raise the high possibility that a subset of NSAIDs may be an effective treatment in the clinical conditions characterized by failure of axonal regeneration, including SCI. These data not only demonstrate the essential role of RhoA in regulating axonal growth failure after a CNS injury but also provide a therapeutic approach to the neurological disorders characterized by white matter damage.

\section{RhoA as a target to promote CNS axonal regeneration}

Regulation of RhoA activity represents an important target for overcoming axon growth inhibition and for developing potent agents for CNS axonal injury treatment (Dergham et al., 2002; 

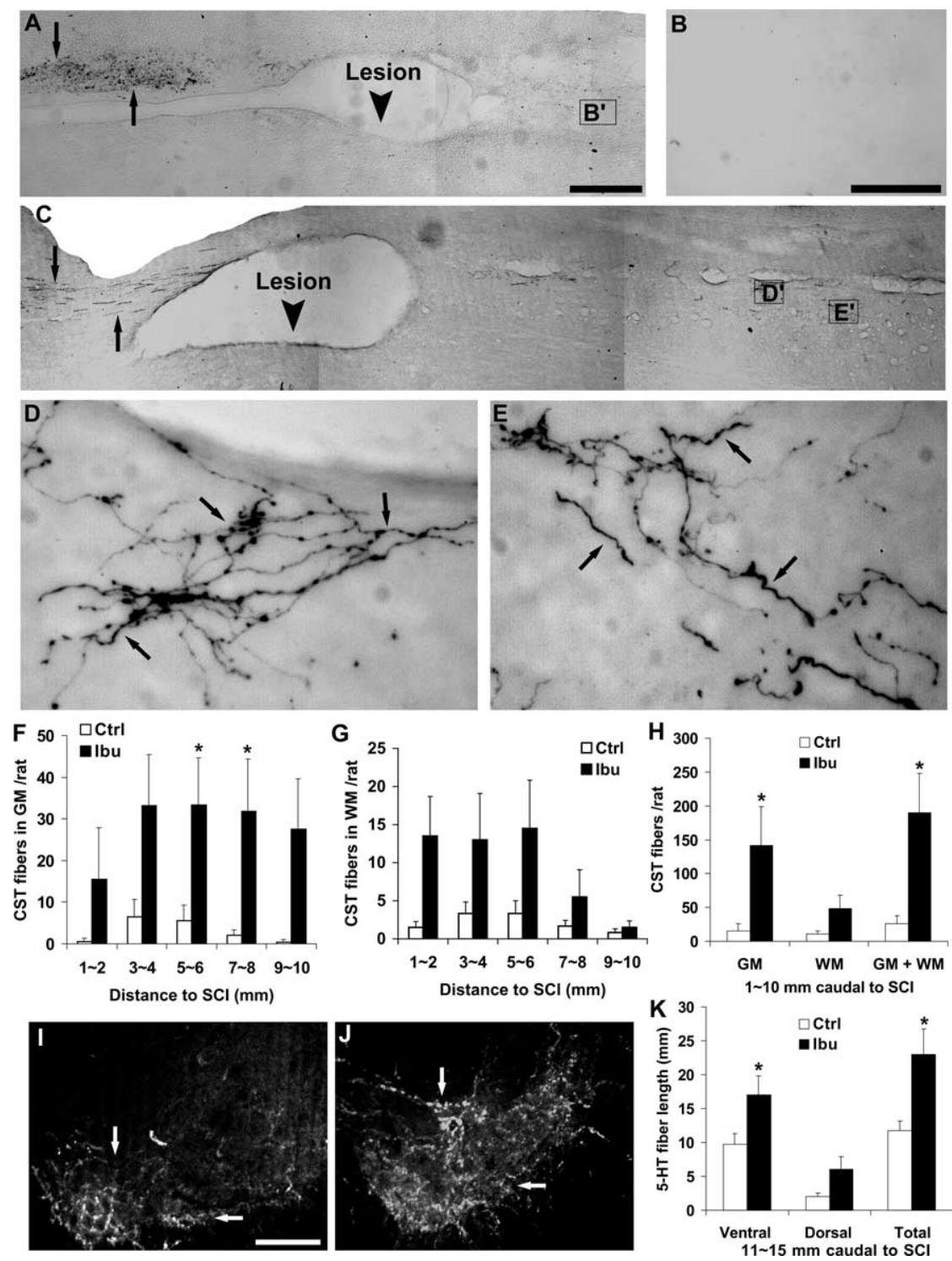

Figure 6. Delayed ibuprofen stimulates CST and serotonergic axon growth after a moderate contusion SCI in rats. $A, B$, Parasagittal sections containing contusion site (arrowhead) from a saline-treated rat demonstrates the large cavity in the lesion epicenter and the termination of BDA-labeled dorsal CST fibers (arrows) above the injury $(\boldsymbol{A})$. No fibers extend into the lesion area or beyond it even at a high magnification $(\boldsymbol{B})$. $\boldsymbol{C}-\boldsymbol{E}$, Sections from an animal receiving a 4 week ibuprofen treatment initiated $7 \mathrm{~d}$ after lesion $\left(60 \mathrm{mg} \cdot \mathrm{kg}^{-1} \cdot \mathrm{d}^{-1}\right)$ display the similar cavities at the injury site, but numerous CST axons (arrows) grew into the walls of cavitation immediately rostral to the injury (C). Many branched sprouting fibers are observed in the areas caudal to the lesion. Higher magnifications of these areas in $\boldsymbol{D}^{\prime}$ and $\boldsymbol{E}^{\prime}$ illustrate the meandering course of regenerating CST fibers in the ibuprofen-treated rat. $\boldsymbol{F}, \boldsymbol{G}$, The number of CST fibers $\geq 200 \mu \mathrm{m}$ in sprout diameter at various distances caudal to the injury from ibuprofen (filled bar) and saline (open bar) rats is reported from gray (GM) $(\boldsymbol{F})$ and white matter (WM) $(\boldsymbol{G})$ areas. $\boldsymbol{H}$, Graph indicates the total CST fibers $1 \sim 10 \mathrm{~mm}$ distal to the lesion reported in $\boldsymbol{F}$ and $\mathbf{G}$. $\boldsymbol{I}, \boldsymbol{J}$, Transverse sections of lumbar spinal cord at $11-15 \mathrm{~mm}$ distal to lesion indicate a higher density of 5 -HT fibers (arrows) in the ventral horn of ibuprofen-treated rat $(J)$ than in the control (I). $\boldsymbol{K}$, Serotonin fiber length in the ventral or dorsal half of the spinal cord per transverse section $11-15 \mathrm{~mm}$ caudal to the injury was quantified. Scale bars: $A, C, 500 \mu \mathrm{m} ; \boldsymbol{B}, \boldsymbol{D}, \boldsymbol{E}, 25 \mu \mathrm{m} ; \boldsymbol{I}, \boldsymbol{J}, 50 \mu \mathrm{m}$. Means \pm SEM are reported ( $n=6$ rats in each of saline and ibuprofen groups). The differences indicated in the bar graphs are statistically different between the two groups ( ${ }^{*} p<0.05$, Student's $t$ test). Ibu, ibuprofen.

Mueller et al., 2005). After a CNS injury, activation of RhoA is the convergent intracellular pathway for numerous extracellular molecules that restrict axonal growth, including CNS myelin, CSPGs, and possibly a few axonal guidance cues during development (Huber et al., 2003; McGee and Strittmatter, 2003). Activation of RhoA signal leads to growth cone collapse and neurite growth inhibition in cultured primary neurons (Kozma et al., 1997; Kranenburg et al., 1999). Inactivation of Rho with C3 trans- ferase, Rho downstream inhibitor Y27632 (Fournier et al., 2003), ibuprofen, or indomethacin (Fig. 3), promotes the neurite outgrowth on myelin or CSPG inhibitory substrates. Moreover, numerous in vivo studies suggest that suppression of Rho signaling pathway is a feasible approach to promote axonal regeneration, to reduce cell death, and to improve functional recovery after rodent CNS injuries including transection and contusion spinal cord injuries, or optic nerve crush injury (Hara et al., 2000; Dergham et al., 2002; Dubreuil et al., 2003; Fournier et al., 2003; Sung et al., 2003; Fischer et al., 2004; Bertrand et al., 2005; Nishio et al., 2006). Notably, Rho inactivation with several cell-permeable versions of C3 (C3-05, C3-07, and BA210) or ROCK inhibition with Y27632 or Fasudil benefits the locomotion recovery of SCI rodents. Of these agents, BA-210 has been under the clinical trial for treating acute SCI patients (McKerracher and Higuchi, 2006). In this report, we provide the additional evidence that Rho silence with ibuprofen remarkably enhances the axonal growth of corticospinal and raphespinal tracts as well as the locomotor functional recovery in the adult rodents with SCI. Thus, the previous reports, together with the present study, support that Rho signal and its downstream kinase are the important therapeutic targets for promoting functional recovery of adult mammals with CNS injuries.

\section{Basis for NSAID-induced axonal growth in the CNS}

The RhoA-inhibiting effect of ibuprofen is most likely to be the basis for the enhanced axonal growth and the improved behavioral recovery in this report, although the molecular mechanism of RhoA inactivation by some NSAIDs remains unclear. First, using the Rho-GTP binding assay with RBD, we directly demonstrate ibuprofen and indomethacin could effectively reverse the increased RhoA activity because of exposure to CNS myelin or CSPG, or after a traumatic CNS injury. Second, only NSAIDs that suppress RhoA activation, such as ibuprofen and indomethacin, are able to stimulate the neurite elongation in cultured DRG neurons. Ibuprofen stimulates a similar degree of neurite outgrowth to RhoA signal inhibition with C3 or Y62732. Moreover, our in vivo studies demonstrate that RhoA-inhibiting ibuprofen significantly promotes the axonal growth of descending tracts and improves the behavioral recovery after the spinal cord lesions in rodents. In contrast, naproxen, a non-RhoArepressing NSAID, failed to stimulate axonal extension under either in vitro or in vivo conditions. 


\section{Improved behavioral recovery in SCI rodents}

The reestablishment of descending connections induced by RhoA-inhibiting ibuprofen seems to contribute to the locomotion recovery in SCI rats. The extent of motor function recovery after SCI depends on the reorganization of segmental circuitry and the restoration of supraspinal input. The segmental mechanism may play a major role in the locomotor recovery in the control SCI rats because of lack of apparent axonal regeneration. However, in the ibuprofen-treated rats, the restoration of supraspinal input to the distal spinal cord might participate in the functional improvement in addition to the enhanced plasticity at segmental level. Treatment with ibuprofen stimulates the axonal growth in spinal cord below the lesion and significantly increases the fiber number of descending corticospinal and raphespinal tracts, which play a role in locomotor recovery after SCI (Weidner et al., 2001; Kim et al., 2004). Actually, it is likely that sprouting and reorganization of other descending fibers, such as rubrospinal axons, may also contribute to the enhanced functional recovery because of the widespread RhoA activation after a CNS trauma (Madura et al., 2004). Blockade of $\mathrm{NgR}$, a receptor that mediates axon growth inhibition upstream to RhoA (Fournier et al., 2003), results in the anatomical specializations consistent with synaptic formation (GrandPre et al., 2002; Li et al., 2004). It is conceivable that suprasegmental input may contribute to neuronal function observed here. Notably, we cannot exclude the possibility that RhoA inactivation with ibuprofen attenuates the apoptotic cell death of oligodendrocytic glia (Dubreuil et al., 2003) and benefits the functional recovery via protecting spared axons from demyelination around lesion.

We found that RhoA inhibition with ibuprofen started 1 week after a contusion SCI could stimulate the descending axonal growth and enhance the locomotor recovery in rats. Our study contrasts with a recent report that did not show significant CST axonal sprouting and behavioral recovery when inhibition of Rho kinase with local Fasudil was started 4 weeks after a contusion injury (Nishio et al., 2006). The different results between our report and the Fasudil study are probably related to the time window of drug deliveries. The activation of RhoA starts a few hours after SCI and seems to reach to peak levels approximately a few days after lesion (Dubreuil et al., 2003). On $7 \mathrm{~d}$ after injury, the time when ibuprofen treatment was initiated, the active RhoA signal was dramatically increased in the lesioned spinal cord (Fig. 4) (Dubreuil et al., 2003). However, the RhoA activation appears to drop to a low level 4 weeks after injury because the enhanced RhoA activity starts to attenu-
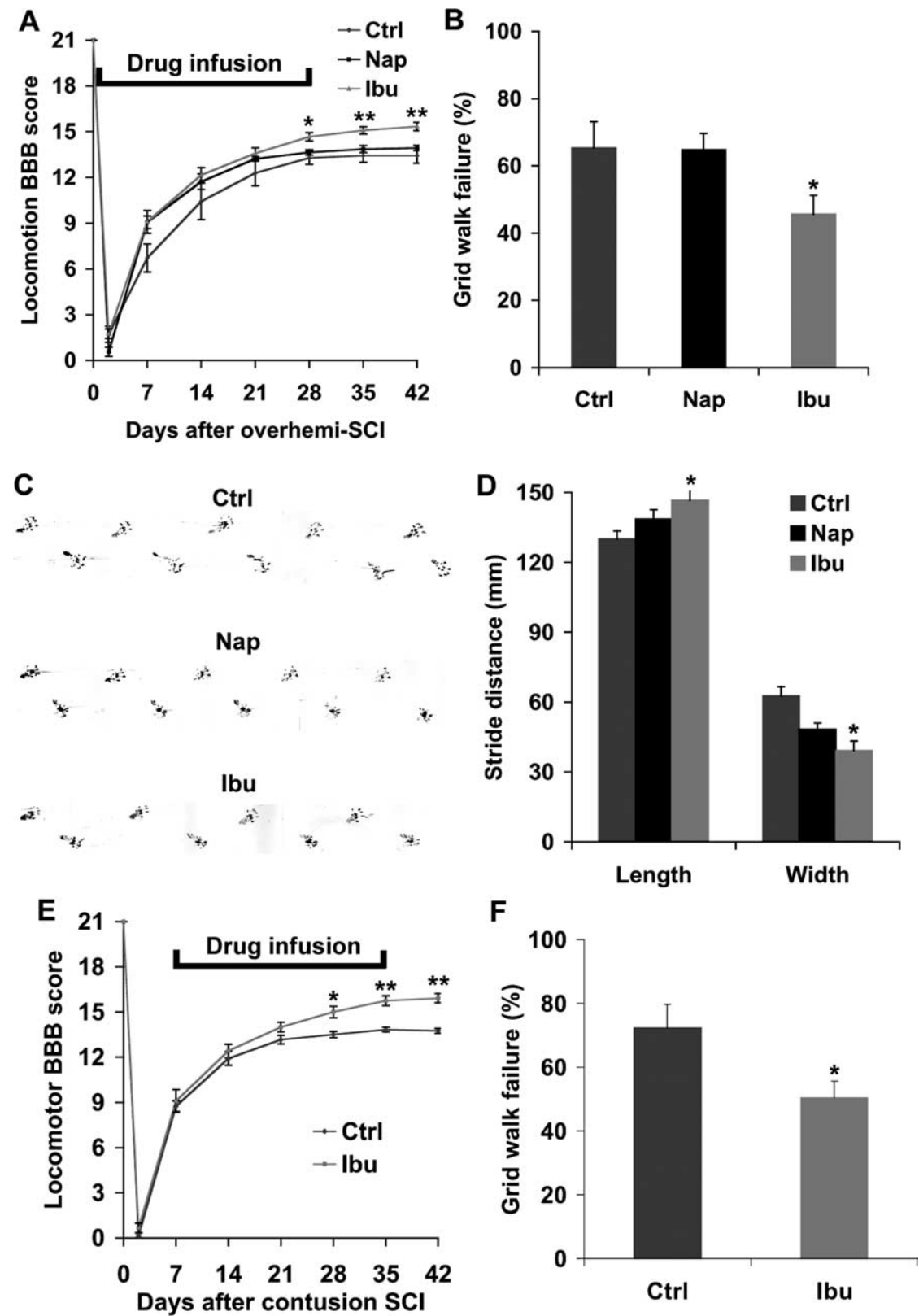

Figure 7. Systemic ibuprofen improves the locomotion behavioral recovery after a transection or a contusion injury in rats. $\boldsymbol{A}$, $\boldsymbol{B}$, Graphs indicate the locomotor BBB score $(\boldsymbol{A})$ and the hindlimb errors during grid walking $(\boldsymbol{B})$ in the vehicle, naproxen, or ibuprofen rats with treatments initiated at the time of a transection injury $(n=7,7,12$ in vehicle, naproxen, and ibuprofen groups). C, The examples of representative footprints from control (top), naproxen (middle), or ibuprofen (bottom) animals after a transection injury. $\boldsymbol{D}$, Footprint analysis reveals a greater stride length and a shorter stride width in ibuprofen-treated animals than in controls. $\boldsymbol{E}, \boldsymbol{F}$, Graphs indicates the BBB score $(\boldsymbol{E})$ and grid walking errors $(\boldsymbol{F})$ in the contusion-injured rats with the treatments (vehicle or ibuprofen) started $7 \mathrm{~d}$ after SCI ( $n=6$ rats/group). Means \pm SEM are reported. The differences indicated are compared with the saline-treated group $\left({ }^{*} p<0.05,{ }^{* *} p<0.01\right.$, Student's $t$ test). Nap, Naproxen; Ibu, ibuprofen.

ate several days after SCI (Dubreuil et al., 2003). It is unlikely that the inherent growth capacity of lesioned motor neurons was further reduced 4 weeks after SCI, because neurotrophic factors combined with fatal spinal cord transplants or with IN1 antibody could stimulate remarkable axonal growth when applied several weeks after rodent SCI (von Meyenburg et al., 1998; Coumans et al., 2001).

Frequent use of NSAIDs in humans as cyclooxygenase inhibitors

COXs (COX-1 and COX-2) are essential for catalyzing the formation of inflammatory prostaglandins from membrane- 
derived arachidonate. The reversible interaction of prostaglandins with G-protein-coupled membrane receptors widely involves the physiological and pathological processes of numerous cell types including neurons (Fitzpatrick, 2004). COX enzymes are clinically important because inhibition of COX by NSAIDs confers the relief from many pathological conditions including inflammatory, thrombotic, neurodegenerative, and oncological disorders. Thus, a great number of NSAIDs including aspirin, ibuprofen, indomethacin, naproxen, and celecoxib are widely used in humans as the pharmacological inhibitors of COX. In the present study, we identified the axon growthpromoting effects of ibuprofen and indomethacin via the Rhosuppressing mechanism independent of COX action. Obviously, the frequent administration of these drugs in humans will facilitate us to apply the Rho-inhibiting NSAIDs to SCI patients. Notably, NSAIDs are dose-dependently associated with several side effects, particularly on the gastrointestine and kidney. Long-term use of NSAIDs in therapy might increase the risk of gastrointestinal ulceration and complications from ulceration including bleeding and perforation. Thus, we also need consider the potential side effects of these agents before applying to SCI patients.

\section{Conclusion and perspectives}

In recent years, a number of researchers have reported the progress in developing intervention strategies in animal SCI models via limiting secondary injury and enhancing fiber sprouting/regeneration and promoting functional recovery. However, few basic science discoveries have been applied clinically to improve behavioral outcomes of axonal injury patients. Thus, it is critical that the promising approaches from basic studies are translatable to effective clinical therapies. In this report, we found that some NSAIDs, the extensively used drugs in the clinic, potently suppressed the increased RhoA activity of neurons exposed to axonal growth inhibitors or after a CNS trauma. Furthermore, the Rho-inhibiting NSAIDs stimulated the remarkable neurite growth in vitro and the descending axonal regeneration in the injured spinal cord in vivo, and enhanced the locomotion recovery. Thus, the novel findings in this report, which can be easily translated to human treatments, will facilitate us to design more rational therapies for CNS axonal injury patients. Together, our studies provide the hope for developing an effective treatment to white matter injury patients including SCI in the near future.

\section{References}

Basso DM, Beattie MS, Bresnahan JC (1995) A sensitive and reliable locomotor rating scale for open field testing in rats. J Neurotrauma 12:1-21.

Benson MD, Romero MI, Lush ME, Lu QR, Henkemeyer M, Parada LF (2005) Ephrin-B3 is a myelin-based inhibitor of neurite outgrowth. Proc Natl Acad Sci USA 102:10694-10699.

Bertrand J, Winton MJ, Rodriguez-Hernandez N, Campenot RB, McKerracher L (2005) Application of rho antagonist to neuronal cell bodies promotes neurite growth in compartmented cultures and regeneration of retinal ganglion cell axons in the optic nerve of adult rats. J Neurosci 25:1113-1121.

Bonilla IE, Tanabe K, Strittmatter SM (2002) Small proline-rich repeat protein $1 \mathrm{~A}$ is expressed by axotomized neurons and promotes axonal outgrowth. J Neurosci 22:1303-1315.

Bracken MB, Shepard MJ, Holford TR, Leo-Summers L, Aldrich EF, Fazl M, Fehlings M, Herr DL, Hitchon PW, Marshall LF, Nockels RP, Pascale V, Perot Jr PL, Piepmeier J, Sonntag VK, Wagner F, Wilberger JE, Winn HR, Young W (1997) Administration of methylprednisolone for 24 or 48 hours or tirilazad mesylate for 48 hours in the treatment of acute spinal cord injury. Results of the Third National Acute Spinal Cord Injury Randomized Controlled Trial. National Acute Spinal Cord Injury Study. JAMA 277:1597-1604.

Bradbury EJ, Moon LD, Popat RJ, King VR, Bennett GS, Patel PN, Fawcett
JW, McMahon SB (2002) Chondroitinase ABC promotes functional recovery after spinal cord injury. Nature 416:636-640.

Chen MS, Huber AB, van der Haar ME, Frank M, Schnell L, Spillmann AA, Christ F, Schwab ME (2000) Nogo-A is a myelin-associated neurite outgrowth inhibitor and an antigen for monoclonal antibody IN-1. Nature 403:434-439.

Coumans JV, Lin TT, Dai HN, MacArthur L, McAtee M, Nash C, Bregman BS (2001) Axonal regeneration and functional recovery after complete spinal cord transection in rats by delayed treatment with transplants and neurotrophins. J Neurosci 21:9334-9344.

David S, Aguayo AJ (1981) Axonal elongation into peripheral nervous system "bridges" after central nervous system injury in adult rats. Science 214:931-933.

Dergham P, Ellezam B, Essagian C, Avedissian H, Lubell WD, McKerracher L (2002) Rho signaling pathway targeted to promote spinal cord repair. J Neurosci 22:6570-6577.

Dubreuil CI, Winton MJ, McKerracher L (2003) Rho activation patterns after spinal cord injury and the role of activated Rho in apoptosis in the central nervous system. J Cell Biol 162:233-243.

Eriksen JL, Sagi SA, Smith TE, Weggen S, Das P, McLendon DC, Ozols VV, Jessing KW, Zavitz KH, Koo EH, Golde TE (2003) NSAIDs and enantiomers of flurbiprofen target gamma-secretase and lower Abeta 42 in vivo. J Clin Invest 112:440-449.

Fischer D, Petkova V, Thanos S, Benowitz LI (2004) Switching mature retinal ganglion cells to a robust growth state in vivo: gene expression and synergy with RhoA inactivation. J Neurosci 24:8726-8740.

Fitzpatrick FA (2004) Cyclooxygenase enzymes: regulation and function. Curr Pharm Des 10:577-588.

Fournier AE, Takizawa BT, Strittmatter SM (2003) Rho kinase inhibition enhances axonal regeneration in the injured CNS. J Neurosci 23:1416-1423.

Goldberg JL, Vargas ME, Wang JT, Mandemakers W, Oster SF, Sretavan DW, Barres BA (2004) An oligodendrocyte lineage-specific semaphorin, Sema5A, inhibits axon growth by retinal ganglion cells. J Neurosci 24:4989-4999.

Goldshmit Y, Galea MP, Wise G, Bartlett PF, Turnley AM (2004) Axonal regeneration and lack of astrocytic gliosis in EphA4-deficient mice. J Neurosci 24:10064-10073.

GrandPre T, Nakamura F, Vartanian T, Strittmatter SM (2000) Identification of the Nogo inhibitor of axon regeneration as a Reticulon protein. Nature 403:439-444.

GrandPre T, Li S, Strittmatter SM (2002) Nogo-66 receptor antagonist peptide promotes axonal regeneration. Nature 417:547-551.

Guth L, Zhang Z, DiProspero NA, Joubin K, Fitch MT (1994a) Spinal cord injury in the rat: treatment with bacterial lipopolysaccharide and indomethacin enhances cellular repair and locomotor function. Exp Neurol 126:76-87.

Guth L, Zhang Z, Roberts E (1994b) Key role for pregnenolone in combination therapy that promotes recovery after spinal cord injury. Proc Natl Acad Sci USA 91:12308-12312.

Hara M, Takayasu M, Watanabe K, Noda A, Takagi T, Suzuki Y, Yoshida J (2000) Protein kinase inhibition by fasudil hydrochloride promotes neurological recovery after spinal cord injury in rats. J Neurosurg 93:94-101.

Huang DW, McKerracher L, Braun PE, David S (1999) A therapeutic vaccine approach to stimulate axon regeneration in the adult mammalian spinal cord. Neuron 24:639-647.

Huber AB, Kolodkin AL, Ginty DD, Cloutier JF (2003) Signaling at the growth cone: ligand-receptor complexes and the control of axon growth and guidance. Annu Rev Neurosci 26:509-563.

Kim JE, Liu BP, Park JH, Strittmatter SM (2004) Nogo-66 receptor prevents raphespinal and rubrospinal axon regeneration and limits functional recovery from spinal cord injury. Neuron 44:439-451.

Kozma R, Sarner S, Ahmed S, Lim L (1997) Rho family GTPases and neuronal growth cone remodelling: relationship between increased complexity induced by $\mathrm{Cdc} 42 \mathrm{Hs}$, Racl, and acetylcholine and collapse induced by RhoA and lysophosphatidic acid. Mol Cell Biol 17:1201-1211.

Kranenburg O, Poland M, van Horck FP, Drechsel D, Hall A, Moolenaar WH (1999) Activation of RhoA by lysophosphatidic acid and Galpha12/13 subunits in neuronal cells: induction of neurite retraction. Mol Biol Cell 10:1851-1857.

Li S, Liu BP, Budel S, Li M, Ji B, Walus L, Li W, Jirik A, Rabacchi S, Choi E, Worley D, Sah DW, Pepinsky B, Lee D, Relton J, Strittmatter SM (2004) 
Blockade of Nogo-66, myelin-associated glycoprotein, and oligodendrocyte myelin glycoprotein by soluble Nogo-66 receptor promotes axonal sprouting and recovery after spinal injury. J Neurosci 24:10511-10520.

Li S, Kim JE, Budel S, Hampton TG, Strittmatter SM (2005) Transgenic inhibition of Nogo-66 receptor function allows axonal sprouting and improved locomotion after spinal injury. Mol Cell Neurosci 29:26-39.

Liu BP, Fournier A, GrandPre T, Strittmatter SM (2002) Myelin-associated glycoprotein as a functional ligand for the Nogo-66 receptor. Science 297:1190-1193.

Madura T, Yamashita T, Kubo T, Fujitani M, Hosokawa K, Tohyama M (2004) Activation of Rho in the injured axons following spinal cord injury. EMBO Rep 5:412-417.

McGee AW, Strittmatter SM (2003) The Nogo-66 receptor: focusing myelin inhibition of axon regeneration. Trends Neurosci 26:193-198.

McKerracher L, Higuchi H (2006) Targeting Rho to stimulate repair after spinal cord injury. J Neurotrauma 23:309-317.

Metz GA, Curt A, van de Meent H, Klusman I, Schwab ME, Dietz V (2000a) Validation of the weight-drop contusion model in rats: a comparative study of human spinal cord injury. J Neurotrauma 17:1-17.

Metz GA, Merkler D, Dietz V, Schwab ME, Fouad K (2000b) Efficient testing of motor function in spinal cord injured rats. Brain Res 883:165-177.

Mi S, Lee X, Shao Z, Thill G, Ji B, Relton J, Levesque M, Allaire N, Perrin S, Sands B, Crowell T, Cate RL, McCoy JM, Pepinsky RB (2004) LINGO-1 is a component of the Nogo-66 receptor/p75 signaling complex. Nat Neurosci 7:221-228.

Mueller BK, Mack H, Teusch N (2005) Rho kinase, a promising drug target for neurological disorders. Nat Rev Drug Discov 4:387-398.

Neumann S, Bradke F, Tessier-Lavigne M, Basbaum AI (2002) Regeneration of sensory axons within the injured spinal cord induced by intraganglionic cAMP elevation. Neuron 34:885-893.

Nishio Y, Koda M, Kitajo K, Seto M, Hata K, Taniguchi J, Moriya H, Fujitani M, Kubo T, Yamashita T (2006) Delayed treatment with Rho-kinase inhibitor does not enhance axonal regeneration or functional recovery after spinal cord injury in rats. Exp Neurol 200:392-397.

Park JB, Yiu G, Kaneko S, Wang J, Chang J, He XL, Garcia KC, He Z (2005) A TNF receptor family member, TROY, is a coreceptor with Nogo receptor in mediating the inhibitory activity of myelin inhibitors. Neuron 45:345-351.

Pearse DD, Pereira FC, Marcillo AE, Bates ML, Berrocal YA, Filbin MT, Bunge MB (2004) cAMP and Schwann cells promote axonal growth and functional recovery after spinal cord injury. Nat Med 10:610-616.

Qiu J, Cai D, Dai H, McAtee M, Hoffman PN, Bregman BS, Filbin MT (2002) Spinal axon regeneration induced by elevation of cyclic AMP. Neuron 34:895-903.

Ren XD, Kiosses WB, Schwartz MA (1999) Regulation of the small GTPbinding protein Rho by cell adhesion and the cytoskeleton. EMBO J 18:578-585.

Rosenzweig ES, McDonald JW (2004) Rodent models for treatment of spinal cord injury: research trends and progress toward useful repair. Curr Opin Neurol 17:121-131.
Schnell L, Schwab ME (1990) Axonal regeneration in the rat spinal cord produced by an antibody against myelin-associated neurite growth inhibitors. Nature 343:269-272.

Shao Z, Browning JL, Lee X, Scott ML, Shulga-Morskaya S, Allaire N, Thill G, Levesque M, Sah D, McCoy JM, Murray B, Jung V, Pepinsky RB, Mi S (2005) TAJ/TROY, an orphan TNF receptor family member, binds Nogo-66 receptor 1 and regulates axonal regeneration. Neuron 45:353-359.

Silver J, Miller JH (2004) Regeneration beyond the glial scar. Nat Rev Neurosci 5:146-156.

Simpson Jr RK, Baskin DS, Dudley AW, Bogue L, Rothenberg F (1991) The influence of long-term nifedipine or indomethacin therapy on neurologic recovery from experimental spinal cord injury. J Spinal Disord 4:420-427.

Sivasankaran R, Pei J, Wang KC, Zhang YP, Shields CB, Xu XM, He Z (2004) PKC mediates inhibitory effects of myelin and chondroitin sulfate proteoglycans on axonal regeneration. Nat Neurosci 7:261-268.

Sung JK, Miao L, Calvert JW, Huang L, Louis Harkey H, Zhang JH (2003) A possible role of RhoA/Rho-kinase in experimental spinal cord injury in rat. Brain Res 959:29-38.

von Meyenburg J, Brosamle C, Metz GA, Schwab ME (1998) Regeneration and sprouting of chronically injured corticospinal tract fibers in adult rats promoted by NT-3 and the mAb IN-1, which neutralizes myelinassociated neurite growth inhibitors. Exp Neurol 154:583-594.

Wang KC, Koprivica V, Kim JA, Sivasankaran R, Guo Y, Neve RL, He Z (2002a) Oligodendrocyte-myelin glycoprotein is a Nogo receptor ligand that inhibits neurite outgrowth. Nature 417:941-944.

Wang KC, Kim JA, Sivasankaran R, Segal R, He Z (2002b) P75 interacts with the Nogo receptor as a co-receptor for Nogo, MAG and OMgp. Nature 420:74-78.

Weggen S, Eriksen JL, Das P, Sagi SA, Wang R, Pietrzik CU, Findlay KA, Smith TE, Murphy MP, Bulter T, Kang DE, Marquez-Sterling N, Golde TE, Koo EH (2001) A subset of NSAIDs lower amyloidogenic Abeta42 independently of cyclooxygenase activity. Nature 414:212-216.

Weidner N, Ner A, Salimi N, Tuszynski MH (2001) Spontaneous corticospinal axonal plasticity and functional recovery after adult central nervous system injury. Proc Natl Acad Sci USA 98:3513-3518.

Winkler T, Sharma HS, Stalberg E, Olsson Y (1993) Indomethacin, an inhibitor of prostaglandin synthesis attenuates alteration in spinal cord evoked potentials and edema formation after trauma to the spinal cord: an experimental study in the rat. Neuroscience 52:1057-1067.

Yan Q, Zhang J, Liu H, Babu-Khan S, Vassar R, Biere AL, Citron M, Landreth G (2003) Anti-inflammatory drug therapy alters $\beta$-amyloid processing and deposition in an animal model of Alzheimer's disease. J Neurosci 23:7504-7509.

Zhou Y, Su Y, Li B, Liu F, Ryder JW, Wu X, Gonzalez-DeWhitt PA, Gelfanova V, Hale JE, May PC, Paul SM, Ni B (2003) Nonsteroidal antiinflammatory drugs can lower amyloidogenic Abeta 42 by inhibiting Rho. Science 302:1215-1217. 